\title{
Systemic inflammation, blood-brain barrier vulnerability and cognitive/non-cognitive symptoms in Alzheimer disease: relevance to pathogenesis and therapy
}

\author{
Shuko Takeda ${ }^{1,2+}{ }^{+}$Naoyuki Sato ${ }^{1,2}{ }^{*}$ and Ryuichi Morishita ${ }^{1}{ }^{*}$ \\ ' Department of Clinical Gene Therapy, Graduate School of Medicine, Osaka University, Yamadaoka, Suita, Osaka, Japan \\ ${ }^{2}$ Department of Geriatric Medicine, Graduate School of Medicine, Osaka University, Yamada-oka, Suita, Osaka, Japan
}

\section{Edited by:}

Brian Joseph Balin, Philadelphia College of Osteopathic Medicine, USA

\section{Reviewed by:}

Ignacio Torres-Aleman, Cajal Institute, Spain

Aurel Popa-Wagner, Clinic of

Psychiatry, Germany

\section{*Correspondence:}

Naoyuki Sato and Ryuichi Morishita,

Department of Clinical Gene

Therapy, Graduate School of

Medicine, Osaka University, 2-2

Yamada-oka, Suita, Osaka

565-0871, Japan

e-mail:nsato@

cgt.med.osaka-u.ac.jp;

morishit@cgt.med.osaka-u.ac.jp

\section{${ }^{\dagger}$ Present address:}

Shuko Takeda, Alzheimer's Disease

Research Laboratory, Department

of Neurology, Mass General Institute

for Neurodegenerative Disease,

Massachusetts General Hospital,

Harvard Medical School,

Charlestown, MA 02129, USA
The incidence of dementia is increasing at an alarming rate, and has become a major public health concern. Alzheimer disease (AD) is the most common form of dementia and is characterized by progressive cognitive impairment. In addition to classical neuropathological features such as amyloid plaques and neurofibrillary tangles (NFT), accumulation of activated immune cells has been documented in the AD brain, suggesting a contribution of neuroinflammation in the pathogenesis of AD. Besides cognitive deterioration, non-cognitive symptoms, such as agitation, aggression, depression and psychosis, are often observed in demented patients, including those with $A D$, and these neuropsychological symptoms place a heavy burden on caregivers. These symptoms often exhibit sudden onset and tend to fluctuate over time, and in many cases, they are triggered by an infection in peripheral organs, suggesting that inflammation plays an important role in the pathogenesis of these non-cognitive symptoms. However, there is no mechanistic explanation for the relationship between inflammation and neuropsychiatric symptoms. Observations from experimental mouse models indicate that alteration of brain blood vessels, especially blood-brain barrier (BBB) dysfunction, may contribute to the relationship. The current review summarizes the results from recent studies on the relationship between inflammation and $A D$, while focusing on cerebrovascular alterations, which might provide an insight into the pathogenesis of cognitive/non-cognitive symptoms in $A D$ patients and suggest a basis for the development of new therapeutic treatments for these conditions.

Keywords: systemic inflammation, blood-brain barrier, Alzheimer disease, pathogenesis, therapy

\section{INTRODUCTION}

Alzheimer disease (AD) is the most common form of dementia, accounting for around $60-90 \%$ of all cases (Thies and Bleiler, 2013), and its incidence is increasing at an alarming rate all over the world. $\mathrm{AD}$ is characterized by progressive cognitive and behavioral impairment, and cerebral deposition of senile plaques (extracellular accumulation of beta-amyloid $(\mathrm{A} \beta)$ peptide) and neurofibrillary tangles (NFTs, intracellular accumulation of hyperphosphorylated tau protein) are unique neuropathological hallmarks of the disease (Hardy and Selkoe, 2002; Iqbal and Grundke-Iqbal, 2006). Multiple so-called "disease-modifying" therapies for $\mathrm{AD}$, such as immunotherapy against $A \beta$, are now under investigation and have been tested in clinical trials; however, most of them have had little success so far (Salloway et al., 2008; Delrieu et al., 2012; Thies and Bleiler, 2013). There is an urgent need to identify novel targets to develop alternative therapeutic strategies.

There is a growing body of evidence linking inflammation and the pathogenesis of $\mathrm{AD}$ (Akiyama et al., 2000; Lee et al., 2010;
Holmes and Butchart, 2011). Microglia, which play a critical role in the brain immune system, are known to be activated in the $\mathrm{AD}$ brain, and clusters of reactive microglia are found associated with amyloid plaque (Serrano-Pozo et al., 2013). Recently, it has been reported that $\mathrm{CD} 33$, which regulates the innate immune system, as well as its gene, has been shown to be a risk factor for $\mathrm{AD}, \mathrm{CD} 33$ inhibits clearance of $\mathrm{A} \beta$ by microglia, and deletion of CD33 in an Alzheimer transgenic mouse significantly reduced pathological amyloid in the brain (Bradshaw et al., 2013; Griciuc et al., 2013). Although the role of neuroinflammation in the $\mathrm{AD}$ brain remains unclear, findings from experimental disease models and clinical studies have demonstrated a significant contribution of inflammation to pathological features and symptoms of $\mathrm{AD}$.

On the other hand, recent epidemiological studies have provided direct evidence linking $\mathrm{AD}$ and vascular risk factors such as hypertension and diabetes mellitus, which is now attracting attention (Takeda et al., 2008; Sato et al., 2011; Sato and Morishita, 2013). Also, it is well recognized that the pathogenesis of $\mathrm{AD}$ and vascular dementia overlap 
(Iadecola, 2010, 2013; Muresanu et al., 2014). Cerebrovascular alteration, which is a common pathological change in these diseases, is a possible mechanism of this relationship. Our recent studies using unique $\mathrm{AD}$ mouse models showed that cerebrovascular inflammation induced by a diabetic condition (Takeda et al., 2010) or peripheral inflammation (Takeda et al., 2013) had a significant impact on pathological features of the $\mathrm{AD}$ brain and cognitive/non-cognitive symptoms of the animals.

In this review, we discuss recent findings on the relationship between inflammation and $\mathrm{AD}$, focusing on cerebrovascular alterations, which might provide a new insight into the pathogenesis of $\mathrm{AD}$ and a basis for the development of an alternative therapeutic strategy for the disease.

\section{AD NEUROPATHOLOGY AND INFLAMMATION}

In addition to classical neuropathological signs like amyloid plaques and NFT, significant accumulation and infiltration of activated immune cells have been well documented in the AD brain (Dickson et al., 1993; Akiyama et al., 2000; Letiembre et al., 2009), suggesting a contribution of neuroinflammation to AD pathogenesis. Clustering of activated microglia (Haga et al., 1989; Simard et al., 2006) and astrocytes (Mrak et al., 1996) around amyloid plaques is observed in the $\mathrm{AD}$ brain, associated with upregulated expression of a variety of inflammatory cytokines, including interleukin (IL)-1 (Griffin et al., 1995), IL-6 (Bauer et al., 1991), tumor necrosis factor- $\alpha$ (TNF- $\alpha$; Tarkowski et al., 1999 ), and transforming growth factor- $\beta$ (TGF- $\beta$; van der Wal et al., 1993). It has been shown that innate immune receptors, such as toll-like receptor and lipopolysaccharide (LPS) receptor (CD14), are upregulated in the human $\mathrm{AD}$ brain (Letiembre et al., 2009). Furthermore, it is well known that most of the $\mathrm{AD}$ transgenic mouse models exhibit significant enhancement of neuroinflammation around amyloid plaques, like those in the human AD brain (Frautschy et al., 1998; Matsuoka et al., 2001; Janelsins et al., 2005), and its severity increases with progression of pathological amyloid with age (Sheng et al., 2000). Importantly, some markers of glial activation are elevated even before the development of amyloid deposition, implying that neuroinflammation precedes typical $\mathrm{AD}$ neuropathological changes and has some causative effect in AD pathogenesis (Sheng et al., 2000). Recent high-resolution positron emission tomographic (PET) imaging has enabled longitudinal observation of amyloid accumulation and associated microglial activation in the Alzheimer amyloid precursor protein (APP) transgenic mouse, and demonstrated a dynamic change in microglial activity in response to anti-amyloid therapy (Maeda et al., 2007; Ji et al., 2008).

However, whether activation of the local immune system in the diseased brain is the cause or consequence of $\mathrm{AD}$, and whether it is causes a positive or negative effect on disease progression remain controversial. It has been reported that direct injection of IL-1 into the rodent brain upregulates beta-APP, supporting the idea that overexpression of IL-1 in the brain could be a driving force in AD pathogenesis (Sheng et al., 1996). Craft et al. (2005) reported that IL-1 receptor antagonist knockout mice, which have enhanced IL-1 signaling, show increased vulnerability to $A \beta$-related toxicity, suggesting that enhanced neuroinflammation mediated by IL-1 could have an unfavorable effect on the AD brain. On the other hand, Shaftel et al. (2007) have shown that local overexpression of IL-1 $\beta$ in the hippocampus of an APP transgenic mouse model significantly decreased the severity of pathological amyloid, demonstrating a possible adaptive role of IL-1 $\beta$ in AD pathogenesis. Similarly, an APP transgenic mouse model overexpressing IL-6 in the brain showed attenuated $\mathrm{A} \beta$ deposition associated with enhanced gliosis, indicating that IL-6-mediated gliosis could have a favorable effect in terms of clearing $A \beta$ from the brain (Chakrabarty et al., 2010). However, Ghosh et al. (2013) also reported that sustained IL- $1 \beta$ overexpression exacerbated pathological tau despite reduced $\mathrm{A} \beta$ burden in an $\mathrm{AD}$ mouse model. These conflicting findings suggest a complex role of inflammation in the $\mathrm{AD}$ brain.

Along the same line, the therapeutic effect of antiinflammatory drugs on human $\mathrm{AD}$ patients is still controversial (McGeer et al., 1996). Findings from experimental studies using mouse model have shown favorable effects of anti-inflammatory agents such as nonsteroidal anti-inflammatory drugs (NSAIDs) on $\mathrm{AD}$ neuropathological features and cognitive disturbance (Lim et al., 2000, 2001; Yan et al., 2003). However, clinical trials of traditional anti-inflammatory drugs, including NSAIDs (Breitner et al., 1994; Rich et al., 1995) and cyclooxygenase (COX) inhibitors (McGeer, 2000; Trepanier and Milgram, 2010), have failed to demonstrate their positive effect on $\mathrm{AD}$ patients (Rogers et al., 1993; Scharf et al., 1999; Aisen et al., 2003; Reines et al., 2004), though it has been claimed that they have lower accessibility into the brain.

\section{SYSTEMIC INFLAMMATION AND AD}

The brain has been considered to be an "immune-privileged" organ, isolated from the peripheral immune system (Shrestha et al., 2013). However, recent evidence shows that there is bidirectional communication between the brain and the peripheral immune system (Holmes and Butchart, 2011). A neural route via the vagal nerve, circumventricular organs that lack a bloodbrain barrier (BBB), direct entry of monocytes through the $\mathrm{BBB}$, and inflammatory lipid mediators such as prostaglandins that can cross the $\mathrm{BBB}$ are recognized to be important communication pathways connecting the brain and the systemic immune system (Quan and Banks, 2007). Alteration of peripheral immune activity can affect the brain immune system through these pathways. In the $\mathrm{AD}$ brain, the $\mathrm{BBB}$ becomes leaky due to damage from accumulation of $\mathrm{A} \beta$ along brain blood vessels (cerebral amyloid angiopathy, CAA) and associated vascular inflammation (Greenberg et al., 2004; Kinnecom et al., 2007), which could alter communication between the brain and the peripheral immune system. Activated peripheral immune cells that enter the brain though the leaky BBB may directly or indirectly affect the central nervous immune system and modulate the pathogenesis of AD. Indeed, Dunn et al. (2005) reported an association between systemic inflammation and increased risk of dementia in a case-control study. Although clinical evidence linking the risk of developing $\mathrm{AD}$ and systemic inflammation is still limited and controversial (Sundelof et al., 
2009), some observational studies and a meta-analysis showed that elevated peripheral inflammatory markers are associated with increased risk of overall dementia (Koyama et al., 2013), suggesting a positive correlation between systemic inflammation and neurodegeneration.

This interaction between the peripheral immune system and the brain might provide a possible explanation for the linkage of some chronic diseases like hypertension in midlife and diabetes, in which persistent inflammation plays a significant role in their pathogenesis, with increased risk of dementia including AD.

\section{INFLAMMATION AND DEMENTIA-ASSOCIATED BEHAVIORAL DISTURBANCE}

Non-cognitive symptoms, such as agitation, aggression, depression and psychosis, are often observed in demented patients including those with $\mathrm{AD}$, in addition to progressive cognitive deterioration. These symptoms, known as "behavioral and psychological symptoms of dementia” (BPSD), have been reported to occur in about $20 \%$ of $\mathrm{AD}$ patients (Lyketsos et al., 2000) and affect up to $80 \%$ of patients living in social care facilities and nursing homes (Margallo-Lana et al., 2001; Ryu et al., 2005), placing an extremely heavy burden on families and caregivers (Corbett et al., 2012; Ballard and Corbett, 2013). These neuropsychological symptoms often exhibit sudden onset and tend to fluctuate over time. In many cases, they are triggered by an acute change in the patient's physical condition such as dehydration, pain, or exacerbation of an existing chronic health condition. Infection in peripheral organs, such as pneumonia or urinary tract infection, is often associated with manifestation of BPSD (Holmes and Butchart, 2011), suggesting that inflammation could play an important role in the pathogenesis underlying these dementia-associated behavioral disturbances. Importantly, severe neuropsychological symptoms triggered by peripheral infection can develop without direct bacterial invasion into the brain spreading from peripheral organs (van Gool et al., 2010) and without signs of sepsis (Ebersoldt et al., 2007). A prospective matched control study has shown a strong association between dementia and postoperative delirium in elderly people who underwent hip surgery, suggesting a link between systemic inflammation induced by peripheral intervention and dementia-associated psychiatric symptoms (Kat et al., 2008). However, at present, specific mechanisms for the susceptibility of demented patients to infection-triggered neuropsychological symptoms have not been proposed.

Some experimental findings using animal models have suggested possible mechanisms for the effect of systemic infection on behavioral disturbance. Acute and chronic infusion of LPS into the rat brain impaired the function of cholinergic neurons, which is essential for maintaining healthy brain function, associated with accumulation of reactive astrocytes and microglia within the basal forebrain (Willard et al., 1999). Godbout et al. reported that LPS-induced peripheral inflammation caused more severe neuroinflammation and associated behavioral disturbances in elderly mice compared to young mice, which indicates that an age-related potential augmentation of neuroinflammatory response might affect the susceptibility to behavioral problems following activation of the peripheral immune system (Godbout et al., 2005; Godbout and Johnson, 2009). The Alzheimer APP transgenic mouse is known to develop a variety of behavioral problems such as diurnal rhythm disturbance and increased aggression resembling BPSD in demented patients (Vloeberghs et al., 2004, 2007), which could be a valuable tool for investigating more specific mechanisms of the neuropsychological symptoms in $\mathrm{AD}$.

\section{BLOOD-BRAIN BARRIER, CEREBROVASCULAR FUNCTION AND NEURODEGENERATIVE DISEASES}

The entry of most molecules into the central nervous system from the peripheral circulation is strictly regulated by the $\mathrm{BBB}$, and its function and integrity are maintained by the "neurovascular unit", which is composed of vascular endothelial cells, astrocytes, pericytes (Hall et al., 2014), and neurons (Bell and Zlokovic, 2009; Neuwelt et al., 2011; Zlokovic, 2011). Brain endothelial cells lining cerebral microvessels act as a physical barrier because they are sealed together by tight junctions, resulting in limited paracellular diffusion, and they have no fenestrations, in contrast to leaky vessels in peripheral organs (Abbott et al., 2006; Ricci et al., 2006). These endothelial cells are surrounded by a basal lamina and the endfeet of astrocytes, which contribute to $\mathrm{BBB}$ function and integrity by regulating expression levels of tight junction molecules (Dehouck et al., 1990) and specific transporters (McAllister et al., 2001). Interactions between endothelial and astroglial cells at the BBB play an important role in maintaining proper brain function by regulating regional cerebral blood flow and metabolism, which could affect local neuronal function (Abbott et al., 2006).

There is emerging evidence that BBB dysfunction is associated with the pathogenesis of a variety of neurodegenerative disorders such as AD (Bell and Zlokovic, 2009; Zlokovic, 2011), Parkinson disease (Chung et al., 2010; Bartels, 2011), multiple sclerosis (Lassmann et al., 2012; Prineas and Parratt, 2012; Tourdias and Dousset, 2013), and amyotrophic lateral sclerosis (Rodrigues et al., 2012; Garbuzova-Davis and Sanberg, 2014; Winkler et al., 2014), in addition to typical cerebrovascular disorders such as stroke and vascular dementia (Wardlaw et al., 2003; Iadecola, 2013).

It has become recognized that there is significant overlap between the pathogenesis of $\mathrm{AD}$ and that of vascular dementia. The results of recent epidemiological studies have shown that vascular risk factors such as hypertension (Skoog and Gustafson, 2003), diabetes mellitus (Ott et al., 1999; Sato et al., 2011) and atherosclerosis (Takeda et al., 2008) have a significant impact on the progression of $\mathrm{AD}$, although the mechanisms underlying these interactions remain unclear. One of the possible explanations for this association is that cerebrovascular damage caused by these diseases could affect cognitive function. Gentile et al. (2009) examined the effect of hypertension on pathological amyloid in the brain using two mouse models of hypertension, demonstrating $A \beta$ deposition in the hypertensive mouse brain which was associated with impairment of BBB integrity. It has been reported that some antihypertensive drugs restored cerebrovascular dysfunction via reduction of oxidative stress and improved cognitive function in an $\mathrm{AD}$ mouse model (Takeda 
et al., 2009). Our previous study demonstrated that, using unique diabetic AD mouse models, co-existence of a diabetic condition could accelerate $A \beta$-related vascular alterations via increased expression of inflammatory cytokines, which was associated with induction of the receptor for advanced glycation end products (RAGE) in the cerebral vasculature (Takeda et al., 2010). These findings imply that cerebrovascular dysfunction plays a role not only in vascular dementia but also in the $\mathrm{AD}$ brain with nongenetic risk factors.

$A p o E-\varepsilon 4$ is a strong genetic risk factor for sporadic AD; however, how it impacts on $\mathrm{AD}$ pathogenesis is still unknown $(\mathrm{Bu}$, 2009). The $A P O E-\varepsilon 4$ allele increases the accumulation of senile plaques in $\mathrm{AD}$ patients as well as in cognitively normal people (Reiman et al., 2009; Morris et al., 2010). One recent report has shown that ApoE also regulates cerebrovascular function via

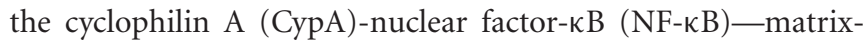
metalloproteinase-9 (MMP9) pathway in pericytes in an isoformspecific manner, and that CypA could be a target for treating ApoE-E4-mediated neurovascular impairment and the related neuronal malfunction (Bell et al., 2012). This observation could provide a new insight for understanding the cerebrovascularrelated pathogenesis of $\mathrm{AD}$, linking the contribution of $A p o E-\varepsilon 4$ as a risk factor.

\section{BBB FUNCTION IN ALZHEIMER BRAIN}

Some studies have shown that BBB integrity is compromised in Alzheimer APP transgenic mice even before they develop amyloid plaques and cognitive impairment. Ujiie et al. (2003) examined BBB integrity in the Tg2576 AD mouse model using a wellestablished method based on dye leakage, and found that $\mathrm{AD}$ mice exhibit breakdown of the $\mathrm{BBB}$ as early as 4 months of age, which is much earlier than the manifestation of amyloid plaque deposition and cognitive dysfunction. This observation implies that functional alteration of the $\mathrm{BBB}$ could be one of the earliest signs of AD. Along the same line, Dickstein et al. (2006) demonstrated that $\mathrm{A} \beta$ immunization therapy could restore $\mathrm{BBB}$ integrity in the same AD mouse model (Tg2576), in addition to improvement of typical $\mathrm{AD}$ brain pathological features such as plaque burden and microgliosis, suggesting a new strategy for $\mathrm{AD}$ treatment focusing on $\mathrm{BBB}$ function (Dickstein et al., 2006). However, we need to give careful consideration to the effect of $\mathrm{A} \beta$ immunization on $\mathrm{BBB}$ function because it has also been demonstrated that passive immunization with $A \beta$ antibodies resulted in a significant increase in both the frequency and severity of CAA-related microhemorrhages in different APP transgenic mouse models (Pfeifer et al., 2002; Racke et al., 2005; Burbach et al., 2007; Luo et al., 2010).

Our recent study has shown that, using an Alzheimer APP transgenic mouse, peripheral inflammation could be more likely to spread into the brain due to increased vulnerability of the blood-brain-barrier to peripherally evoked inflammation, leading to more severe non-cognitive symptoms (Takeda et al., 2013). After peripheral injection of LPS to induce systemic inflammation, APP transgenic mice showed a greater increase in inflammatory cytokine levels in brain interstitial fluid and more severe non-cognitive symptoms (such as attenuation of basal activity, social interaction behavior, and food intake) compared to wild-type control animals, while there was no difference in inflammatory cytokine levels in plasma and peripheral organs between genotypes. The BBB became leaky in the AD transgenic mouse brain during the course of inflammation, suggesting increased vulnerability of the BBB to systemic inflammation in the AD mouse brain, which might be a mechanism for peripheral inflammation spreading more easily to the brain. Importantly, no clear change in brain $A \beta$ level was observed after peripheral administration of LPS, meaning that the behavioral symptoms induced by peripherally evoked inflammation may not be due to change in brain $A \beta$ level. These findings indicate that the potential vulnerability of the $\mathrm{BBB}$ to inflammation underlies the increased severity of behavioral impairment in AD.

The detailed mechanisms of BBB breakdown during systemic inflammation in the $\mathrm{AD}$ mouse brain remain unclear and need to be elucidated in order to tackle this pathological event. The relationship between $A \beta$ and endothelial cells has been under extensive investigation and there is substantial evidence that $A \beta$ could alter endothelial function, which plays a critical role in BBB integrity (Suhara et al., 2003; Vagnucci and Li, 2003; Hayashi et al., 2009; Takeda et al., 2009). It has been demonstrated in vitro that intracellular $A \beta 42$ could be toxic to endothelial cells via disruption of the Akt/glycogen synthase kinase (GSK)-3 $\beta$ pathway (Suhara et al., 2003). Hayashi et al. (2009) also reported that A $\beta 40$ altered endothelial function and impaired vascular regeneration through the induction of autophagy. Another report showed that oxidative stress was increased in brain blood vessels of an APP transgenic mouse (APP23 mouse) even before the manifestation of amyloid plaques and CAA (Takeda et al., 2009). These changes in the cerebral vasculature might potentially increase the vulnerability of the BBB in the $\mathrm{AD}$ brain.

\section{SUMMARY}

A growing body of evidence links systemic inflammation and $\mathrm{AD}$ pathogenesis in the brain. Although the overall impact of the activated brain immune system on $\mathrm{AD}$ pathological features is complicated and still controversial, it is clear that it could be affected by the peripheral immune system. Direct or indirect modulation of the brain immune system from the periphery could be a new strategy to alter $\mathrm{AD}$ progression. The cerebral vasculature, especially the $\mathrm{BBB}$, is an important interface linking peripheral inflammation and the $\mathrm{AD}$ brain (Figure 1). It remains unclear how exactly systemic inflammation could damage the integrity and function of the BBB and alter cognitive function, and the mechanisms need to be elucidated in order to develop new treatments for AD focusing on vascular and other interface pathology.

Moreover, there is a clear cause-and-effect relationship between activated systemic inflammation and the development of neuropsychiatric symptoms in $\mathrm{AD}$, although no mechanistic explanation for the relationship exists thus far. Furthermore, to date, there is no alternative treatment for non-cognitive symptoms of dementia directed against specific pathological mechanisms. Inflammation-related cerebrovascular alterations such as BBB breakdown could be a potential target for new therapies tackling those symptoms. 

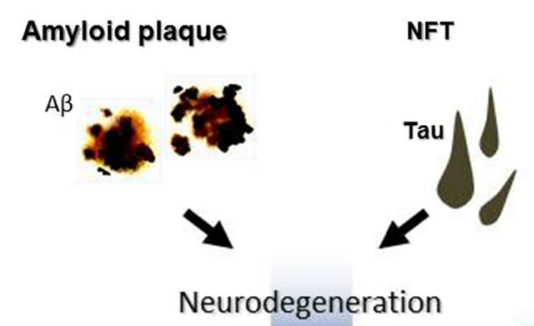

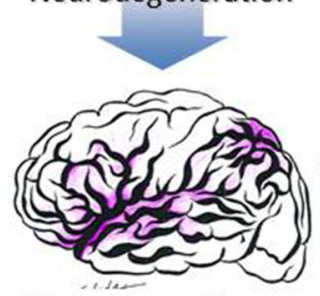

Alzheimer disease

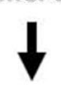

Memory loss, Language problems, etc.
Peripheral inflammation

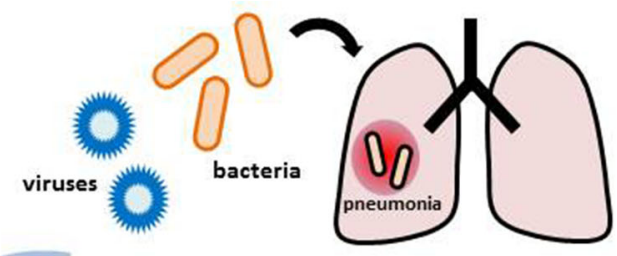

Peripheral infection

BBB

\section{Neuro-inflammation}

\section{Acute behavioral / emotional changes}

\section{Cognitive symptoms}

FIGURE 1 | Neuropathological features, inflammation, and cognitive/non-cognitive symptoms of Alzheimer disease. Cerebral accumulation of amyloid plaques and neurofibrillary tangles (NFT) leads to neurodegeneration in the AD brain, which causes progressive cognitive dysfunction such as memory loss and language problems. Non-cognitive
Non-cognitive symptoms

\section{ACKNOWLEDGMENTS}

Shuko Takeda is supported by a fellowship from the Japan Society for the Promotion of Science (JSPS). This work was supported in part by grants-in-aid from Japan Promotion of Science, the Japanese Ministry of Education, Culture, Sports, Science and Technology (to Naoyuki Sato. and Ryuichi Morishita), the Japan Science and Technology Agency (to Naoyuki Sato), Novartis Gerontological Research Grants and the Takeda Science Foundation (to Naoyuki Sato).

\section{REFERENCES}

Abbott, N. J., Ronnback, L., and Hansson, E. (2006). Astrocyte-endothelial interactions at the blood-brain barrier. Nat. Rev. Neurosci. 7, 41-53. doi: 10. 1038/nrn1824

Aisen, P. S., Schafer, K. A., Grundman, M., Pfeiffer, E., Sano, M., Davis, K. L., et al. (2003). Effects of rofecoxib or naproxen vs placebo on Alzheimer disease progression: a randomized controlled trial. JAMA 289, 2819-2826. doi: 10. 1001/jama.289.21.2819

Akiyama, H., Barger, S., Barnum, S., Bradt, B., Bauer, J., Cole, G. M., et al. (2000). Inflammation and Alzheimer's disease. Neurobiol. Aging 21, 383-421. doi: 10. 1016/S0197-4580(00)00124-X

Ballard, C., and Corbett, A. (2013). Agitation and aggression in people with Alzheimer's disease. Curr. Opin. Psychiatry 26, 252-259. doi: 10.1097/YCO. 0b013e32835f414b

Bartels, A. L. (2011). Blood-brain barrier P-glycoprotein function in neurodegenerative disease. Curr. Pharm. Des. 17, 2771-2777. doi: 10.2174/ 138161211797440122

Bauer, J., Strauss, S., Schreiter-Gasser, U., Ganter, U., Schlegel, P., Witt, I., et al. (1991). Interleukin-6 and alpha-2-macroglobulin indicate an acute-phase state in Alzheimer's disease cortices. FEBS Lett. 285, 111-114. doi: 10.1016/00145793(91)80737-n symptoms, such as agitation, aggression and psychosis, are often observed in AD patients, besides cognitive deterioration. These symptoms can be triggered by an infection in peripheral organs such as pneumonia, suggesting a contribution of peripheral inflammation. BBB, blood-brain barrier.
Bell, R. D., Winkler, E. A., Singh, I., Sagare, A. P., Deane, R., Wu, Z., et al. (2012). Apolipoprotein E controls cerebrovascular integrity via cyclophilin A. Nature 485, 512-516. doi: 10.1038/nature11087

Bell, R. D., and Zlokovic, B. V. (2009). Neurovascular mechanisms and blood-brain barrier disorder in Alzheimer's disease. Acta Neuropathol. 118, 103-113. doi: 10. 1007/s00401-009-0522-3

Bradshaw, E. M., Chibnik, L. B., Keenan, B. T., Ottoboni, L., Raj, T., Tang, A., et al. (2013). CD33 Alzheimer's disease locus: altered monocyte function and amyloid biology. Nat. Neurosci. 16, 848-850. doi: 10.1038/nn.3435

Breitner, J. C., Gau, B. A., Welsh, K. A., Plassman, B. L., McDonald, W. M., Helms, M. J., et al. (1994). Inverse association of anti-inflammatory treatments and Alzheimer's disease: initial results of a co-twin control study. Neurology 44, 227232. doi: 10.1212/wnl.44.2.227

Bu, G. (2009). Apolipoprotein E and its receptors in Alzheimer's disease: pathways, pathogenesis and therapy. Nat. Rev. Neurosci. 10, 333-344. doi: 10.1038/ nrn2620

Burbach, G. J., Vlachos, A., Ghebremedhin, E., Del Turco, D., Coomaraswamy, J., Staufenbiel, M., et al. (2007). Vessel ultrastructure in APP23 transgenic mice after passive anti-Abeta immunotherapy and subsequent intracerebral hemorrhage. Neurobiol. Aging 28, 202-212. doi: 10.1016/j.neurobiolaging.2005. 12.003

Chakrabarty, P., Jansen-West, K., Beccard, A., Ceballos-Diaz, C., Levites, Y., Verbeeck, C., et al. (2010). Massive gliosis induced by interleukin-6 suppresses Abeta deposition in vivo: evidence against inflammation as a driving force for amyloid deposition. FASEB J. 24, 548-559. doi: 10.1096/fj.09-141754

Chung, Y. C., Ko, H. W., Bok, E., Park, E. S., Huh, S. H., Nam, J. H., et al. (2010). The role of neuroinflammation on the pathogenesis of Parkinson's disease. BMB Rep. 43, 225-232. doi: 10.5483/bmbrep.2010.43.4.225

Corbett, A., Smith, J., Creese, B., and Ballard, C. (2012). Treatment of behavioral and psychological symptoms of Alzheimer's disease. Curr. Treat. Options Neurol. 14, 113-125. doi: 10.1007/s11940-012-0166-9

Craft, J. M., Watterson, D. M., Hirsch, E., and Van Eldik, L. J. (2005). Interleukin 1 receptor antagonist knockout mice show enhanced microglial activation and 
neuronal damage induced by intracerebroventricular infusion of human betaamyloid. J. Neuroinflammation 2:15. doi: 10.1186/1742-2094-2-15

Dehouck, M. P., Meresse, S., Delorme, P., Fruchart, J. C., and Cecchelli, R. (1990). An easier, reproducible and mass-production method to study the blood-brain barrier in vitro. J. Neurochem. 54, 1798-1801. doi: 10.1111/j.1471-4159.1990. tb01236.x

Delrieu, J., Ousset, P. J., Caillaud, C., and Vellas, B. (2012). 'Clinical trials in Alzheimer's disease': immunotherapy approaches. J. Neurochem. 120(Suppl. 1), 186-193. doi: 10.1111/j.1471-4159.2011.07458.x

Dickson, D. W., Lee, S. C., Mattiace, L. A., Yen, S. H., and Brosnan, C. (1993). Microglia and cytokines in neurological disease, with special reference to AIDS and Alzheimer's disease. Glia 7, 75-83. doi: 10.1002/glia.440070113

Dickstein, D. L., Biron, K. E., Ujiie, M., Pfeifer, C. G., Jeffries, A. R., and Jefferies, W. A. (2006). Abeta peptide immunization restores blood-brain barrier integrity in Alzheimer disease. FASEB J. 20, 426-433. doi: 10.1096/fj.05-3956com

Dunn, N., Mullee, M., Perry, V. H., and Holmes, C. (2005). Association between dementia and infectious disease: evidence from a case-control study. Alzheimer Dis. Assoc. Disord. 19, 91-94. doi: 10.1097/01.wad.0000165511. 52746.1f

Ebersoldt, M., Sharshar, T., and Annane, D. (2007). Sepsis-associated delirium. Intensive Care Med. 33, 941-950. doi: 10.1007/s00134-007-0622-2

Frautschy, S. A., Yang, F., Irrizarry, M., Hyman, B., Saido, T. C., Hsiao, K., et al. (1998). Microglial response to amyloid plaques in APPsw transgenic mice. Am. J. Pathol. 152, 307-317.

Garbuzova-Davis, S., and Sanberg, P. R. (2014). Blood-CNS barrier impairment in ALS patients versus an animal model. Front. Cell. Neurosci. 8:21. doi: 10. 3389/fncel.2014.00021

Gentile, M. T., Poulet, R., Di Pardo, A., Cifelli, G., Maffei, A., Vecchione, C., et al. (2009). Beta-amyloid deposition in brain is enhanced in mouse models of arterial hypertension. Neurobiol. Aging 30, 222-228. doi: 10.1016/j.neurobiolaging. 2007.06.005

Ghosh, S., Wu, M. D., Shaftel, S. S., Kyrkanides, S., LaFerla, F. M., Olschowka, J. A., et al. (2013). Sustained interleukin-1beta overexpression exacerbates tau pathology despite reduced amyloid burden in an Alzheimer's mouse model. J. Neurosci. 33, 5053-5064. doi: 10.1523/JNEUROSCI.4361-12.2013

Godbout, J. P., Chen, J., Abraham, J., Richwine, A. F., Berg, B. M., Kelley, K. W., et al. (2005). Exaggerated neuroinflammation and sickness behavior in aged mice following activation of the peripheral innate immune system. FASEB J. 19, 1329-1331. doi: 10.1096/fj.05-3776fje

Godbout, J. P., and Johnson, R. W. (2009). Age and neuroinflammation: a lifetime of psychoneuroimmune consequences. Immunol. Allergy Clin. North Am. 29, 321-337. doi: 10.1016/j.iac.2009.02.007

Greenberg, S. M., Gurol, M. E., Rosand, J., and Smith, E. E. (2004). Amyloid angiopathy-related vascular cognitive impairment. Stroke 35, 2616-2619. doi: 10.1161/01.str.0000143224.36527.44

Griciuc, A., Serrano-Pozo, A., Parrado, A. R., Lesinski, A. N., Asselin, C. N., Mullin, K., et al. (2013). Alzheimer's disease risk gene CD33 inhibits microglial uptake of amyloid beta. Neuron 78, 631-643. doi: 10.1016/j.neuron.2013.04.014

Griffin, W. S., Sheng, J. G., Roberts, G. W., and Mrak, R. E. (1995). Interleukin1 expression in different plaque types in Alzheimer's disease: significance in plaque evolution. J. Neuropathol. Exp. Neurol. 54, 276-281. doi: 10. 1097/00005072-199503000-00014

Haga, S., Akai, K., and Ishii, T. (1989). Demonstration of microglial cells in and around senile (neuritic) plaques in the Alzheimer brain. An immunohistochemical study using a novel monoclonal antibody. Acta Neuropathol. 77, 569-575. doi: $10.1007 / \mathrm{bf} 00687883$

Hall, C. N., Reynell, C., Gesslein, B., Hamilton, N. B., Mishra, A., Sutherland, B. A., et al. (2014). Capillary pericytes regulate cerebral blood flow in health and disease. Nature 508, 55-60. doi: 10.1038/nature13165

Hardy, J., and Selkoe, D. J. (2002). The amyloid hypothesis of Alzheimer's disease: progress and problems on the road to therapeutics. Science 297, 353-356. doi: 10.1126/science.1072994

Hayashi, S., Sato, N., Yamamoto, A., Ikegame, Y., Nakashima, S., Ogihara, T., et al. (2009). Alzheimer disease-associated peptide, amyloid beta40, inhibits vascular regeneration with induction of endothelial autophagy. Arterioscler. Thromb. Vasc. Biol. 29, 1909-1915. doi: 10.1161/ATVBAHA.109.188516

Holmes, C., and Butchart, J. (2011). Systemic inflammation and Alzheimer's disease. Biochem. Soc. Trans. 39, 898-901. doi: 10.1042/BST0390898
Iadecola, C. (2010). The overlap between neurodegenerative and vascular factors in the pathogenesis of dementia. Acta Neuropathol. 120, 287-296. doi: 10. 1007/s00401-010-0718-6

Iadecola, C. (2013). The pathobiology of vascular dementia. Neuron 80, 844-866. doi: 10.1016/j.neuron.2013.10.008

Iqbal, K., and Grundke-Iqbal, I. (2006). Discoveries of tau, abnormally hyperphosphorylated tau and others of neurofibrillary degeneration: a personal historical perspective. J. Alzheimers Dis. 9, 219-242.

Janelsins, M. C., Mastrangelo, M. A., Oddo, S., LaFerla, F. M., Federoff, H. J., and Bowers, W. J. (2005). Early correlation of microglial activation with enhanced tumor necrosis factor-alpha and monocyte chemoattractant protein-1 expression specifically within the entorhinal cortex of triple transgenic Alzheimer's disease mice. J. Neuroinflammation 2:23. doi: 10.1186/1742-2094-2-23

Ji, B., Maeda, J., Sawada, M., Ono, M., Okauchi, T., Inaji, M., et al. (2008). Imaging of peripheral benzodiazepine receptor expression as biomarkers of detrimental versus beneficial glial responses in mouse models of Alzheimer's and other CNS pathologies. J. Neurosci. 28, 12255-12267. doi: 10.1523/JNEUROSCI.2312-08. 2008

Kat, M. G., Vreeswijk, R., de Jonghe, J. F., van der Ploeg, T., van Gool, W. A., Eikelenboom, P., et al. (2008). Long-term cognitive outcome of delirium in elderly hip surgery patients. A prospective matched controlled study over two and a half years. Dement. Geriatr. Cogn. Disord. 26, 1-8. doi: 10.1159/000140611

Kinnecom, C., Lev, M. H., Wendell, L., Smith, E. E., Rosand, J., Frosch, M. P., et al. (2007). Course of cerebral amyloid angiopathy-related inflammation. Neurology 68, 1411-1416. doi: 10.1212/01.wnl.0000260066.98681.2e

Koyama, A., O’Brien, J., Weuve, J., Blacker, D., Metti, A. L., and Yaffe, K. (2013). The role of peripheral inflammatory markers in dementia and Alzheimer's disease: a meta-analysis. J. Gerontol. A Biol. Sci. Med. Sci. 68, 433-440. doi: 10. 1093/gerona/gls187

Lassmann, H., van Horssen, J., and Mahad, D. (2012). Progressive multiple sclerosis: pathology and pathogenesis. Nat. Rev. Neurol. 8, 647-656. doi: 10. 1038/nrneurol.2012.168

Lee, Y. J., Han, S. B., Nam, S. Y., Oh, K. W., and Hong, J. T. (2010). Inflammation and Alzheimer's disease. Arch. Pharm. Res. 33, 1539-1556. doi: 10.1007/s12272010-1006-7

Letiembre, M., Liu, Y., Walter, S., Hao, W., Pfander, T., Wrede, A., et al. (2009). Screening of innate immune receptors in neurodegenerative diseases: a similar pattern. Neurobiol. Aging 30, 759-768. doi: 10.1016/j.neurobiolaging.2007. 08.018

Lim, G. P., Yang, F., Chu, T., Chen, P., Beech, W., Teter, B., et al. (2000). Ibuprofen suppresses plaque pathology and inflammation in a mouse model for Alzheimer's disease. J. Neurosci. 20, 5709-5714.

Lim, G. P., Yang, F., Chu, T., Gahtan, E., Ubeda, O., Beech, W., et al. (2001). Ibuprofen effects on Alzheimer pathology and open field activity in APPsw transgenic mice. Neurobiol. Aging 22, 983-991. doi: 10.1016/s0197-4580(01)00299-8

Luo, F., Rustay, N. R., Seifert, T., Roesner, B., Hradil, V., Hillen, H., et al. (2010). Magnetic resonance imaging detection and time course of cerebral microhemorrhages during passive immunotherapy in living amyloid precursor protein transgenic mice. J. Pharmacol. Exp. Ther. 335, 580-588. doi: 10.1124/jpet.110. 172932

Lyketsos, C. G., Steinberg, M., Tschanz, J. T., Norton, M. C., Steffens, D. C., and Breitner, J. C. (2000). Mental and behavioral disturbances in dementia: findings from the cache county study on memory in aging. Am. J. Psychiatry 157, 708714. doi: 10.1176/appi.ajp.157.5.708

Maeda, J., Ji, B., Irie, T., Tomiyama, T., Maruyama, M., Okauchi, T., et al. (2007). Longitudinal, quantitative assessment of amyloid, neuroinflammation and anti-amyloid treatment in a living mouse model of Alzheimer's disease enabled by positron emission tomography. J. Neurosci. 27, 10957-10968. doi: 10. 1523/jneurosci.0673-07.2007

Margallo-Lana, M., Swann, A., O’Brien, J., Fairbairn, A., Reichelt, K., Potkins, D., et al. (2001). Prevalence and pharmacological management of behavioural and psychological symptoms amongst dementia sufferers living in care environments. Int. J. Geriatr. Psychiatry 16, 39-44. doi: 10.1002/10991166(200101) 16:1<39::aid-gps269>3.0.co;2-f

Matsuoka, Y., Picciano, M., Malester, B., LaFrancois, J., Zehr, C., Daeschner, J. M., et al. (2001). Inflammatory responses to amyloidosis in a transgenic mouse model of Alzheimer's disease. Am. J. Pathol. 158, 1345-1354. doi: 10.1016/s00029440(10)64085-0 
McAllister, M. S., Krizanac-Bengez, L., Macchia, F., Naftalin, R. J., Pedley, K. C., Mayberg, M. R., et al. (2001). Mechanisms of glucose transport at the bloodbrain barrier: an in vitro study. Brain Res. 904, 20-30. doi: 10.1016/s00068993(01)02418-0

McGeer, P. L. (2000). Cyclo-oxygenase-2 inhibitors: rationale and therapeutic potential for Alzheimer's disease. Drugs Aging 17, 1-11. doi: 10.2165/00002512200017010-00001

McGeer, P. L., Schulzer, M., and McGeer, E. G. (1996). Arthritis and antiinflammatory agents as possible protective factors for Alzheimer's disease: a review of 17 epidemiologic studies. Neurology 47, 425-432. doi: 10.1212/wnl. 47.2.425

Morris, J. C., Roe, C. M., Xiong, C., Fagan, A. M., Goate, A. M., Holtzman, D. M., et al. (2010). APOE predicts amyloid-beta but not tau Alzheimer pathology in cognitively normal aging. Ann. Neurol. 67, 122-131. doi: 10.1002/ana.21843

Mrak, R. E., Sheng, J. G., and Griffin, W. S. (1996). Correlation of astrocytic S100 beta expression with dystrophic neurites in amyloid plaques of Alzheimer's disease. J. Neuropathol. Exp. Neurol. 55, 273-279. doi: 10.1097/00005072199603000-00002

Muresanu, D. F., Popa-Wagner, A., Stan, A., Buga, A. M., and Popescu, B. O. (2014). The vascular component of Alzheimer's disease. Curr. Neurovasc. Res. 11, 168 176. doi: 10.2174/1567202611666140408105333

Neuwelt, E. A., Bauer, B., Fahlke, C., Fricker, G., Iadecola, C., Janigro, D., et al. (2011). Engaging neuroscience to advance translational research in brain barrier biology. Nat. Rev. Neurosci. 12, 169-182. doi: 10.1038/nrn2995

Ott, A., Stolk, R. P., van Harskamp, F., Pols, H. A., Hofman, A., and Breteler, M. M. (1999). Diabetes mellitus and the risk of dementia: the rotterdam study. Neurology 53, 1937-1942. doi: 10.1212/WNL.53.9.1937

Pfeifer, M., Boncristiano, S., Bondolfi, L., Stalder, A., Deller, T., Staufenbiel, M., et al. (2002). Cerebral hemorrhage after passive anti-Abeta immunotherapy. Science 298:1379. doi: 10.1126/science.1078259

Prineas, J. W., and Parratt, J. D. (2012). Oligodendrocytes and the early multiple sclerosis lesion. Ann. Neurol. 72, 18-31. doi: 10.1002/ana.23634

Quan, N., and Banks, W. A. (2007). Brain-immune communication pathways. Brain Behav. Immun. 21, 727-735. doi: 10.1016/j.bbi.2007.05.005

Racke, M. M., Boone, L. I., Hepburn, D. L., Parsadainian, M., Bryan, M. T., Ness, D. K., et al. (2005). Exacerbation of cerebral amyloid angiopathyassociated microhemorrhage in amyloid precursor protein transgenic mice by immunotherapy is dependent on antibody recognition of deposited forms of amyloid beta. J. Neurosci. 25, 629-636. doi: 10.1523/jneurosci.4337-04.2005

Reiman, E. M., Chen, K., Liu, X., Bandy, D., Yu, M., Lee, W., et al. (2009). Fibrillar amyloid- $\beta$ burden in cognitively normal people at 3 levels of genetic risk for Alzheimer's disease. Proc. Natl. Acad. Sci. US A 106, 6820-6825. doi: 10. 1073/pnas.0900345106

Reines, S. A., Block, G. A., Morris, J. C., Liu, G., Nessly, M. L., Lines, C. R., et al. (2004). Rofecoxib: no effect on Alzheimer's disease in a 1-year, randomized, blinded, controlled study. Neurology 62, 66-71. doi: 10.1212/wnl.62.1.66

Ricci, M., Blasi, P., Giovagnoli, S., and Rossi, C. (2006). Delivering drugs to the central nervous system: a medicinal chemistry or a pharmaceutical technology issue? Curr. Med. Chem. 13, 1757-1775. doi: 10.2174/0929867067774 52461

Rich, J. B., Rasmusson, D. X., Folstein, M. F., Carson, K. A., Kawas, C., and Brandt, J. (1995). Nonsteroidal anti-inflammatory drugs in Alzheimer's disease. Neurology 45, 51-55. doi: 10.1212/WNL.45.1.51

Rodrigues, M. C., Hernandez-Ontiveros, D. G., Louis, M. K., Willing, A. E., Borlongan, C. V., Sanberg, P. R., et al. (2012). Neurovascular aspects of amyotrophic lateral sclerosis. Int. Rev. Neurobiol. 102, 91-106. doi: 10.1016/B978-012-386986-9.00004-1

Rogers, J., Kirby, L. C., Hempelman, S. R., Berry, D. L., McGeer, P. L., Kaszniak, A. W., et al. (1993). Clinical trial of indomethacin in Alzheimer's disease. Neurology 43, 1609-1611. doi: 10.1212/WNL.43.8.1609

Ryu, S. H., Katona, C., Rive, B., and Livingston, G. (2005). Persistence of and changes in neuropsychiatric symptoms in Alzheimer disease over 6 months: the LASER-AD study. Am. J. Geriatr. Psychiatry 13, 976-983. doi: 10.1097/ 00019442-200511000-00008

Salloway, S., Mintzer, J., Weiner, M. F., and Cummings, J. L. (2008). Diseasemodifying therapies in Alzheimer's disease. Alzheimers Dement. 4, 65-79. doi: 10.1016/j.jalz.2007.10.001

Sato, N., and Morishita, R. (2013). Roles of vascular and metabolic components in cognitive dysfunction of Alzheimer disease: short- and long-term modification by non-genetic risk factors. Front. Aging Neurosci. 5:64. doi: 10.3389/fnagi.2013. 00064

Sato, N., Takeda, S., Uchio-Yamada, K., Ueda, H., Fujisawa, T., Rakugi, H., et al. (2011). Role of insulin signaling in the interaction between Alzheimer disease and diabetes mellitus: a missing link to therapeutic potential. Curr. Aging Sci. 4, 118-127. doi: 10.2174/1874609811104020118

Scharf, S., Mander, A., Ugoni, A., Vajda, F., and Christophidis, N. (1999). A doubleblind, placebo-controlled trial of diclofenac/misoprostol in Alzheimer's disease. Neurology 53, 197-201. doi: 10.1212/wnl.53.1.197

Serrano-Pozo, A., Muzikansky, A., Gomez-Isla, T., Growdon, J. H., Betensky, R. A., Frosch, M. P., et al. (2013). Differential relationships of reactive astrocytes and microglia to fibrillar amyloid deposits in Alzheimer disease. J. Neuropathol. Exp. Neurol. 72, 462-471. doi: 10.1097/NEN.0b013e3182933788

Shaftel, S. S., Kyrkanides, S., Olschowka, J. A., Miller, J. N., Johnson, R. E., and O'Banion, M. K. (2007). Sustained hippocampal IL-1 beta overexpression mediates chronic neuroinflammation and ameliorates Alzheimer plaque pathology. J. Clin. Invest. 117, 1595-1604. doi: 10.1172/jci31450

Sheng, J. G., Ito, K., Skinner, R. D., Mrak, R. E., Rovnaghi, C. R., Van Eldik, L. J., et al. (1996). In vivo and in vitro evidence supporting a role for the inflammatory cytokine interleukin-1 as a driving force in Alzheimer pathogenesis. Neurobiol. Aging 17, 761-766. doi: 10.1016/s0197-4580(96)00104-2

Sheng, J. G., Mrak, R. E., Bales, K. R., Cordell, B., Paul, S. M., Jones, R. A., et al. (2000). Overexpression of the neuritotrophic cytokine S100beta precedes the appearance of neuritic beta-amyloid plaques in APPV717F mice. J. Neurochem. 74, 295-301. doi: 10.1046/j.1471-4159.2000.0740295.x

Shrestha, R., Millington, O., Brewer, J., and Bushell, T. (2013). Is central nervous system an immune-privileged site? Kathmandu Univ. Med. J. (KUMJ) 11, $102-107$.

Simard, A. R., Soulet, D., Gowing, G., Julien, J. P., and Rivest, S. (2006). Bone marrow-derived microglia play a critical role in restricting senile plaque formation in Alzheimer's disease. Neuron 49, 489-502. doi: 10.1016/j.neuron.2006. 01.022

Skoog, I., and Gustafson, D. (2003). Hypertension, hypertension-clustering factors and Alzheimer's disease. Neurol. Res. 25, 675-680. doi: 10.1179/ 016164103101201986

Suhara, T., Magrane, J., Rosen, K., Christensen, R., Kim, H. S., Zheng, B., et al. (2003). Abeta42 generation is toxic to endothelial cells and inhibits eNOS function through an Akt/GSK-3beta signaling-dependent mechanism. Neurobiol. Aging 24, 437-451. doi: 10.1016/s0197-4580(02)00135-5

Sundelof, J., Kilander, L., Helmersson, J., Larsson, A., Ronnemaa, E., DegermanGunnarsson, M., et al. (2009). Systemic inflammation and the risk of Alzheimer's disease and dementia: a prospective population-based study. $J$. Alzheimers Dis. 18, 79-87. doi: 10.3233/JAD-2009-1126

Takeda, S., Sato, N., Ikimura, K., Nishino, H., Rakugi, H., and Morishita, R. (2013). Increased blood-brain barrier vulnerability to systemic inflammation in an Alzheimer disease mouse model. Neurobiol. Aging 34, 2064-2070. doi: 10.1016/j. neurobiolaging.2013.02.010

Takeda, S., Sato, N., Ogihara, T., and Morishita, R. (2008). The renin-angiotensin system, hypertension and cognitive dysfunction in Alzheimer's disease: new therapeutic potential. Front. Biosci. 13, 2253-2265. doi: 10.2741/2839

Takeda, S., Sato, N., Takeuchi, D., Kurinami, H., Shinohara, M., Niisato, K., et al. (2009). Angiotensin receptor blocker prevented beta-amyloid-induced cognitive impairment associated with recovery of neurovascular coupling. Hypertension 54, 1345-1352. doi: 10.1161/HYPERTENSIONAHA.109.138586

Takeda, S., Sato, N., Uchio-Yamada, K., Sawada, K., Kunieda, T., Takeuchi, D., et al. (2010). Diabetes-accelerated memory dysfunction via cerebrovascular inflammation and Abeta deposition in an Alzheimer mouse model with diabetes. Proc. Natl. Acad. Sci. U S A 107, 7036-7041. doi: 10.1073/pnas. 1000645107

Tarkowski, E., Blennow, K., Wallin, A., and Tarkowski, A. (1999). Intracerebral production of tumor necrosis factor-alpha, a local neuroprotective agent, in Alzheimer disease and vascular dementia. J. Clin. Immunol. 19, 223-230. doi: 10. 1023/A:1020568013953

Thies, W., Bleiler, L., and Alzheimer's Association. (2013). 2013 Alzheimer's disease facts and figures. Alzheimers Dement. 9, 208-245. doi: 10.5538/1137-1242. 2013.54

Tourdias, T., and Dousset, V. (2013). Neuroinflammatory imaging biomarkers: relevance to multiple sclerosis and its therapy. Neurotherapeutics 10, 111-123. doi: 10.1007/s13311-012-0155-4 
Trepanier, C. H., and Milgram, N. W. (2010). Neuroinflammation in Alzheimer's disease: are NSAIDs and selective COX-2 inhibitors the next line of therapy? J. Alzheimers Dis. 21, 1089-1099. doi: 10.3233/JAD-2010-090667

Ujiie, M., Dickstein, D. L., Carlow, D. A., and Jefferies, W. A. (2003). Blood-brain barrier permeability precedes senile plaque formation in an Alzheimer disease model. Microcirculation 10, 463-470. doi: 10.1038/sj.mn.7800212

Vagnucci, A. H., Jr., and Li, W. W. (2003). Alzheimer's disease and angiogenesis. Lancet 361, 605-608. doi: 10.1016/S0140-6736(03)12521-4

van der Wal, E. A., Gomez-Pinilla, F., and Cotman, C. W. (1993). Transforming growth factor-beta 1 is in plaques in Alzheimer and down pathologies. Neuroreport 4, 69-72. doi: 10.1097/00001756-199301000-00018

van Gool, W. A., van de Beek, D., and Eikelenboom, P. (2010). Systemic infection and delirium: when cytokines and acetylcholine collide. Lancet 375, 773-775. doi: 10.1016/S0140-6736(09)61158-2

Vloeberghs, E., Van Dam, D., Engelborghs, S., Nagels, G., Staufenbiel, M., and De Deyn, P. P. (2004). Altered circadian locomotor activity in APP23 mice: a model for BPSD disturbances. Eur. J. Neurosci. 20, 2757-2766. doi: 10.1111/j. 1460-9568.2004.03755.x

Vloeberghs, E., Van Dam, D., Franck, F., Staufenbiel, M., and De Deyn, P. P. (2007). Mood and male sexual behaviour in the APP23 model of Alzheimer's disease. Behav. Brain Res. 180, 146-151. doi: 10.1016/j.bbr.2007.03.002

Wardlaw, J. M., Sandercock, P. A., Dennis, M. S., and Starr, J. (2003). Is breakdown of the blood-brain barrier responsible for lacunar stroke, leukoaraiosis and dementia? Stroke 34, 806-812. doi: 10.1161/01.str.0000058480.77236.b3

Willard, L. B., Hauss-Wegrzyniak, B., and Wenk, G. L. (1999). Pathological and biochemical consequences of acute and chronic neuroinflammation within the basal forebrain cholinergic system of rats. Neuroscience 88, 193-200. doi: 10 . 1016/s0306-4522(98)00216-4
Winkler, E. A., Sengillo, J. D., Sagare, A. P., Zhao, Z., Ma, Q., Zuniga, E., et al. (2014). Blood-spinal cord barrier disruption contributes to early motor-neuron degeneration in ALS-model mice. Proc. Natl. Acad. Sci. U S A 111, E1035-E1042. doi: 10.1073/pnas.1401595111

Yan, Q., Zhang, J., Liu, H., Babu-Khan, S., Vassar, R., Biere, A. L., et al. (2003). Antiinflammatory drug therapy alters beta-amyloid processing and deposition in an animal model of Alzheimer's disease. J. Neurosci. 23, 7504-7509.

Zlokovic, B. V. (2011). Neurovascular pathways to neurodegeneration in Alzheimer's disease and other disorders. Nat. Rev. Neurosci. 12, 723-738. doi: 10. $10381 /$ nrn3114

Conflict of Interest Statement: The authors declare that the research was conducted in the absence of any commercial or financial relationships that could be construed as a potential conflict of interest.

Received: 19 May 2014; paper pending published: 12 June 2014; accepted: 01 July 2014; published online: 29 July 2014.

Citation: Takeda S, Sato N and Morishita R (2014) Systemic inflammation, bloodbrain barrier vulnerability and cognitive/non-cognitive symptoms in Alzheimer disease: relevance to pathogenesis and therapy. Front. Aging Neurosci. 6:171. doi: 10.3389/fnagi.2014.00171

This article was submitted to the journal Frontiers in Aging Neuroscience.

Copyright (C) 2014 Takeda, Sato and Morishita. This is an open-access article distributed under the terms of the Creative Commons Attribution License (CC BY). The use, distribution or reproduction in other forums is permitted, provided the original author(s) or licensor are credited and that the original publication in this journal is cited, in accordance with accepted academic practice. No use, distribution or reproduction is permitted which does not comply with these terms. 